\title{
Research
}

\section{Addressing cannabis use in primary care: GPs' knowledge of cannabis-related harm and current practice}

Ian Wilson Primary Care Coordinator (Substance Misuse), Wandsworth Primary Care Trust, London, Matthew Whiting Researcher, Wandsworth Primary Care Research Centre, Wandsworth Primary Care Trust, London and Amy Scammell Research Manager, Wandsworth Primary Care Research Centre, Wandsworth Primary Care Trust, London, UK

\begin{abstract}
General practice is a principal point of access for individuals who experience problems associated with cannabis use, including dependence on the drug. However, there are no clear guidelines on advice or clinical interventions for primary care practitioners regarding this area. Whilst it has been suggested that specific services to deal with cannabis users are required (Stephens et al., 1993) we have neither a clear idea of how many individuals in local populations may need support to give up or reduce cannabis use, nor of the knowledge or practice of GPs in relation to patients that use cannabis. This study examined GPs' knowledge of cannabis-related harm, and their own responses and practice in treating patients who present for help. A postal questionnaire was sent to 155 general practitioners in Wandsworth, of which 97 (63\%) completed questionnaires were returned. The results showed that GPs in Wandsworth are aware of the risks associated with cannabis use, and are also motivated to improve their knowledge base. Attitudes towards the appropriate setting and approach to treatment interventions were mixed, with some believing that cannabis users could be treated in primary care and others preferring onward referral to specialist drug ser-vices. However, given that $46 \%(n=47)$ of our sample had been approached by a patient wishing to stop using cannabis, effective primary care interventions are required. The study argues for improved primary care engagement with cannabis users seeking support via clear guidelines and training of practitioners, improved signposting to specialist services and shared care, and further consideration of issues around the recording of information relating to cannabis use. In addition, more national and strategic clarity regarding the potential harm of using cannabis, as well as treatment options and care pathways would be welcomed.
\end{abstract}

Keywords: cannabis; GP; interventions; risks

Received: April 2006; accepted: March 2007

\section{Introduction}

Cannabis is the most commonly used illicit drug in the UK. In 2004, it had a considerably higher

Correspondence to: Ian Wilson, Wandsworth Primary Care Trust Headquarters, Teak Tower, Springfield University Hospital Glenburnie Road, Tooting, London, SW17 7DJ, UK.Email: ian.wilson@wpct.nhs.uk prevalence rate compared to other drugs: $10.8 \%$ compared to $2.0 \%$ ecstasy, the second most prevalent drug (Eaton et al., 2005). Although the UK has historically had the highest rates of cannabis use in Europe, the situation has stabilized since the late 1990s, with the UK now having the fourth highest prevalence rate in Europe (Eaton et al., 2005). 


\section{Health impacts}

Cannabis has anxiolytic, sedative, analgesic and psychedelic properties, and thus affects many bodily systems. Psychologically, it can produce euphoric or dysphoric effects, perceptual changes and cognitive impairment. It can also induce more severe symptoms including paranoia and hallucinations. There is a body of evidence supporting a link between cannabis use and the subsequent development of schizophrenia (Andreasson et al., 1987; Mathers and Ghodse, 1992; Linszen et al., 1994; Fergusson et al., 2005), as well as depression and anxiety (Bovasso, 2001; Patton et al., 2002). However, the argument for a causal link between cannabis and onset of schizophrenia remains controversial. A more frequently accepted explanation is that cannabis can trigger the onset or relapse of illness in individuals predisposed to psychiatric conditions, and can exacerbate symptoms in those already diagnosed (Rey and Tennant, 2002).

Systemically, the cardiovascular and respiratory systems are most affected, with cannabis inducing tachycardia, vaso-dilation, reddening of the conjunctiva, and postural hypotension. Rare cases of acute and sometimes fatal myocardial infarctions have been reported in young cannabis smokers (Ashton, 2001). The respiratory effects are a public health concern, particularly when considering that most cannabis in the UK is smoked in combin-ation with tobacco. It has been estimated that the tar inhaled and retained from cannabis joints can be three times higher than that of a cigarette (Henry, 2003). Individuals who smoke cannabis and tobacco together also appear to have higher rates of adverse respiratory symptoms (Hall, 1998). However, the evidence remains equivocal about the carcinogenic effects of cannabis smoke. While it has been reported that cannabis smoke contains more of some carcinogens than tobacco smoke (Wu et al.,1988), more recent reviews have not found a link between cannabis smoke and tobacco-related cancers (eg, Hashibe et al., 2005; Melamede, 2005).

\section{Dependence}

Despite early views that cannabis was not a drug of dependence, research on animals and chronic cannabis users have provided increasing evidence for its dependence potential (Iverson, 2000) as defined under the ICD-10 classification system (eg, Swift et al., 1998). Hall and Solowij (1998) suggest that dependence on cannabis is the most prevalent and under-appreciated risk for regular cannabis users, claiming that about $10 \%$ of those who ever use cannabis, and between one third and half of those who use it daily, will have difficulty in controlling their use, and will continue to use the drug despite attributing problems to it. In addition it has been suggested that cannabis may act as a 'gateway' drug leading to the use of other illicit drugs (Fergusson and Horwood, 2000).

Despite the above issues, there remains a widespread belief, especially among young people, that cannabis is harmless (Ashton, 2001). This may be reinforced by the recent re-classification of cannabis from a class ' $\mathrm{B}$ ' to a class ' $\mathrm{C}$ ' drug, and wellpublicized debates on decriminalization. Negative views of cannabis are also counteracted by evidence for a variety of therapeutic benefits of cannabinoids in some medical conditions, for example relief for glaucoma sufferers, HIV/AIDS and musculoskeletal disorders (Robson, 1998). This highlights the fact that the effects of cannabinoids are complex and can appear contradictory, resulting in polarized views about its use in society.

\section{Service provision and treatment for cannabis users}

In the UK there are different models of treatment for drug misuse depending on the drug and the treatment setting. Some services are exclusively abstinence focussed, such as smoking cessation services, most residential detoxification or rehabilitation units, and self-help groups like Alcoholics Anonymous or Marijuana Anonymous. The alternative approach to abstinence is 'harm reduction', currently favoured within the treatment sector (eg, National Treatment Agency, 2005). Harm reduction is an approach that covers activities and services that acknowledge the continued drug use of individuals, but to seek to minimize the harm that such behaviour causes (Drugscope, 2000). Abstinence may be seen as the desired end point of the spectrum of harm reduction, although reductions in drug use are seen as positive outcomes if abstinence is not achievable.

The government's national drugs strategy (Home Office, 2002) clearly outlines an expectation of greater primary care involvement with drug misuse treatment, although there is little guidance as to what model or form this may take for cannabis

Primary Health Care Research \& Development 2007; 8: 216-225 
misuse. Psychosocial interventions and brief cognitive behavioural therapy (CBT) have good outcomes in significantly reducing cannabis use and associated problems including dependence (Stephens et al., 1994; Copeland et al., 2001). Despite this and the indication of demand for specific treatment centres or clinics for cannabis misuse (Stephens et al., 1994), these are rare. In addition, as cannabis is mainly smoked with tobacco, an individual's perhaps unacknowledged addiction to nicotine may also need to be addressed. Whilst smoking cessation services are now widely available, their role in assisting individuals who smoke cannabis is unclear. As Henry (2003) noted, prevention and cessation are the two principal strategies in the battle against tobacco, yet at present there is no clear public health message concerning cannabis use.

\section{This study}

It could be expected that any individuals experiencing difficulties associated with cannabis use will initially access their local GP practice for help. This raises the question of how primary healthcare practitioners, including GPs, respond to the issue of cannabis misuse in their patient population. Whilst there is research examining GPs' attitudes to drug use in general (eg, Glanz, 1986a; 1986b; McGillion et al., 2000; Kmietowicz, 2002; Matheson et al., 2003), little has been undertaken relating to GPs' attitudes to cannabis use or their knowledge of the effects of cannabis.

Wandsworth is one of the largest boroughs in the Greater London area. Its geographic location, new and strong housing sector combined with business expansion has attracted many young, healthy, wealthy and highly educated people. Many residents are identified as single with one-person households reaching 37\%. Wandsworth has a very high proportion of young residents between the ages of 20 and 44 (53\% compared to national average of $35 \%$ ) with a diverse ethnic profile and high rates of mobility (Wandsworth Primary Care Trust, 2004). This profile presents a number of challenges for managing the health of the population. Cannabis use is most prevalent within younger age groups, such as those overrepresented in Wandsworth, making this a well-suited borough for further study. In addition, discussions with primary care practitioners in Wandsworth PCT highlighted anecdotal evidence that cannabis misuse was a concern within Wandsworth PCT and that GPs' methods of managing cannabis misuse varied widely.

This study aimed to survey GPs' knowledge of cannabis-related harm and their responses to patients' presenting with cannabis use problems. It also aimed to generate discussion about the treatment of cannabis use problems and the involvement of primary care professionals in such treatment.

\section{Methodology}

This study used a quantitative survey approach. An information letter and questionnaire was sent to all 155 partner and salaried GPs in Wandsworth PCT. Reminder letters and additional copies of the questionnaire were posted to non-responders after a period of two weeks and also distributed via email, as a further reminder. In total, $63 \%(n=97)$ of questionnaires were completed and returned.

The questionnaire examined three different areas:

1) GPs' history of treating patients for cannabis dependence and any clinical interventions they had used, adapted from Glanz's (1986a; 1986b) survey of GPs' responses to patients presenting with opiate dependence.

2) GPs' attitudes regarding the potential harm of cannabis use.

3) GPs' confidence in their knowledge and clinical skills to treat individuals using cannabis.

The questionnaire items comprised closed answer questions and five-point Likert scales ranging from 'strongly disagree' to 'strongly agree'.

The questionnaire was piloted with a sample group of ten GPs, following discussion of the content with researchers in St. George's Hospital Medical School, and evaluated against a checklist for questionnaire surveys (De Vaus, 2002). Comments from the pilot GPs were used to finalise the questionnaire for the main sample.

All data were analysed using SPSS version 12.0. Descriptive statistics were undertaken along with Pearson's correlations and independent t-tests. All statistical tests were assigned a significance level of $<0.05$. 
Ethical approval for the study was received from Wandsworth Research Ethics Committee prior to commencement.

\section{Results}

The results are divided into four sections. The first section discusses GPs' history of treating cannabis use, the second section discusses GPs' attitudes to potential cannabis-related harm, the third section covers GPs' attitudes towards their knowledge and clinical skills to treat cannabis dependence and the final section examines the GPs' attitudes to treating cannabis dependence in a primary care setting.

\section{GPs' history of treating cannabis use}

Forty-six per cent $(n=45)$ of GPs stated that a patient had approached them for help to stop using cannabis. We asked about the interventions and treatment routes followed by those GPs who had treated patients for cannabis use in the past. Eighty-four per cent $(n=38)$ of GPs who had treated patients for cannabis use reported assessing the patients' needs through an interview and recording their history of cannabis use. Most respondents referred the patient to a specialist service. Almost $67 \%(n=30)$ of respondents had referred a cannabis-using patient to an NHS specialist drug service, $53 \%(n=24)$ had referred a patient to local voluntary sector (non-NHS) services, almost $29 \%(n=13)$ had referred a patient to a Primary Care Liaison Worker, $18 \%$ had referred a presenting patient to psychiatric services, and $2 \%(n=1)$ had referred a patient for cannabis use to social services. However, 33\% $(n=15)$ had managed the problem in a primary care setting.

Independent t-tests were undertaken to compare differences between GPs who had been consulted by patients who wanted help to stop using cannabis, and those who had not. GPs who had been consulted for help to stop using cannabis agreed more strongly with the statements 'I feel confident in my ability to advise patients concerning their cannabis use' $(t=-2.024$, df $=95, P<0.05)$ and 'it would be useful to ask about cannabis as part of a new patient check' $(t=2.871$, df $=95, P<0.05)$. No other significant relationships were evident.

\section{GPs' attitudes to potential cannabis-related harm}

The findings indicate that GPs believe that cannabis use does pose a potential health risk, as shown in Table 1. Just under $90 \%$ of GPs $(n=87)$ disagreed that 'cannabis is a harmless drug'. More than $80 \%(n=79)$ disagreed that 'cannabis is not a drug on which people can become dependent'. In addition to concerns regarding its potential for harm and dependence, only $12 \%(n=12)$ of respondents felt that 'cannabis use does not lead an individual to experiment with harder drugs'.

Table 1 GPs' responses to attitude statements regarding the potential harm of cannabis use

\begin{tabular}{|c|c|c|c|c|c|}
\hline & $\begin{array}{l}\text { Strongly } \\
\text { agree }(n)\end{array}$ & Agree $(n)$ & $\begin{array}{l}\text { Neither agree } \\
\text { nor disagree }(n)\end{array}$ & Disagree $(n)$ & $\begin{array}{l}\text { Strongly } \\
\text { disagree }(n)\end{array}$ \\
\hline Cannabis is a harmless drug & $4.1(4)$ & $1.0(1)$ & $5.2(5)$ & $37.1(36)$ & $52.6(51)$ \\
\hline $\begin{array}{l}\text { Cannabis is not a drug on which } \\
\text { people can become dependent }\end{array}$ & $6.2(6)$ & $2.1(2)$ & $10.3(10)$ & $38.1(37)$ & $43.3(42)$ \\
\hline $\begin{array}{l}\text { Cannabis use does not lead an } \\
\text { individual to experiment with } \\
\text { 'harder' drugs }\end{array}$ & $1.0(1)$ & $11.3(11)$ & $27.8(27)$ & $39.2(38)$ & $20.6(20)$ \\
\hline $\begin{array}{l}\text { Smoking cannabis and tobacco is } \\
\text { more harmful than smoking alone }\end{array}$ & $39.2(38)$ & $28.9(28)$ & $19.6(19)$ & $6.2(6)$ & $6.2(6)$ \\
\hline $\begin{array}{l}\text { Smoking cannabis would be OK if } \\
\text { it was not for the tobacco that is } \\
\text { smoked with it }\end{array}$ & $1.0(1)$ & $2.1(2)$ & $12.4(12)$ & $47.4(46)$ & $37.1(36)$ \\
\hline $\begin{array}{l}\text { Cannabis use does not lead to } \\
\text { mental health complications }\end{array}$ & $3.1(3)$ & $1.0(1)$ & $3.1(3)$ & $37.1(36)$ & $55.7(54)$ \\
\hline $\begin{array}{c}\text { There is a link between cannabis } \\
\text { use and onset of schizophrenia }\end{array}$ & $19.6(19)$ & $42.3(41)$ & $26.8(26)$ & $11.3(11)$ & - \\
\hline $\begin{array}{l}\text { Prescribed cannabis should be } \\
\text { allowed to treat certain medical } \\
\text { conditions }\end{array}$ & $18.6(18)$ & $36.1(35)$ & $29.9(29)$ & $13.4(13)$ & $2.1(2)$ \\
\hline
\end{tabular}


Many GPs indicated that harm was related to how cannabis was used, with over $68 \%(n=66)$ agreeing that 'smoking cannabis and tobacco together is more harmful than smoking tobacco alone', and $85 \%(n=82)$ rejecting the idea that 'smoking cannabis would be okay if it wasn't for the tobacco it is smoked with'. When asked about their attitudes towards links between cannabis use and mental health problems, almost $93 \%(n=90)$ refuted the claim that 'cannabis use does not lead to mental health complications' and $62 \%(n=60)$ agreed that 'there is a link between cannabis use and the onset of schizophrenia'. However, in spite of these indications of harm, almost $55 \%(n=53)$ of GPs felt that 'prescribed cannabis should be allowed to treat certain medical conditions'.

\section{GPs' attitudes towards their own knowledge and clinical interventions}

Respondents' confidence in their own ability to treat cannabis use and respondents' attitudes towards appropriate clinical interventions varied within the sample. Just over 35\% $(n=34)$ of GPs indicated feeling 'confident in my ability to advise patients concerning cannabis use', while $38 \%$ $(n=37)$ felt unconfident. Over $48 \%(n=47)$ felt they did, "not have adequate knowledge of the potential risks associated with cannabis use', and similarly $66 \% \quad(n=64)$ said 'I would like to improve my knowledge of the potential risks associated with cannabis use'. The majority of GPs $(73 \%, n=71)$ expressed the view that they would rather know if a patient was using cannabis. Fiftyfive per cent $(n=53)$ felt 'it would be useful to ask about cannabis use as part of a new patient check'.

When asking about clinical interventions GPs' responses were more mixed. Whilst over $45 \%$ $(n=44)$ felt that 'abstinence is the best advice I can give my patients' many $(37 \%, n=36)$ neither agreed nor disagreed. Whilst 39\% $(n=40)$ felt that harm reduction is a useful approach in treating cannabis use, again a high proportion had no opinion $(47 \%, n=46)$ (Table 2$)$.

\section{Treating cannabis dependence in primary care}

Respondents were asked about the appropriateness of primary care as a setting for treating

Table 2 GPs' responses to attitude statements regarding their knowledge and skills of clinical interventions to treat cannabis use

\begin{tabular}{|c|c|c|c|c|c|}
\hline & $\begin{array}{l}\text { Strongly } \\
\text { agree }(n)\end{array}$ & Agree $(n)$ & $\begin{array}{l}\text { Neither agree } \\
\text { nor disagree }(n)\end{array}$ & Disagree $(n)$ & $\begin{array}{l}\text { Strongly } \\
\text { disagree }(n)\end{array}$ \\
\hline $\begin{array}{l}\text { I feel confident in my ability to } \\
\text { advise patients concerning their } \\
\text { cannabis use }\end{array}$ & $5.2(5)$ & $29.9(29)$ & $26.8(26)$ & $30.9(30)$ & $7.2(7)$ \\
\hline $\begin{array}{l}\text { I do not have adequate knowledge } \\
\text { of the potential risks associated } \\
\text { with cannabis use }\end{array}$ & $9.3(9)$ & $39.2(38)$ & $24.7(24)$ & $21.6(21)$ & $5.2(5)$ \\
\hline $\begin{array}{l}\text { I would rather not know if my } \\
\text { patients are smoking cannabis }\end{array}$ & $3.1(3)$ & $7.2(7)$ & $16.5(16)$ & $54.6(53)$ & $18.6(18)$ \\
\hline $\begin{array}{l}\text { It would be useful to ask about } \\
\text { cannabis use as part of a 'new } \\
\text { patient check' }\end{array}$ & $12.4(12)$ & $42.3(41)$ & $22.7(22)$ & 17.5 (17) & $5.2(5)$ \\
\hline $\begin{array}{l}\text { People presenting to general practice } \\
\text { with cannabis-related problems } \\
\text { should be referred to specialist } \\
\text { drug services }\end{array}$ & $18.6(18)$ & $39.2(38)$ & 19.6 (19) & 19.6 (19) & $3.1(3)$ \\
\hline $\begin{array}{l}\text { It is appropriate to treat cannabis } \\
\text { dependence in primary care }\end{array}$ & $6.2(6)$ & $27.8(27)$ & $23.7(23)$ & 23.7 (23) & $18.6(18)$ \\
\hline
\end{tabular}

Primary Health Care Research \& Development 2007; 8: 216-225 
cannabis misuse as well as being asked about strategies for treating cannabis misuse. Almost 58\% $(n=56)$ of GPs felt that 'people presenting to general practice with cannabis-related problems should be referred to specialist drug services' while $13 \%$ $(n=13)$ disagreed. However, 34\% $(n=33)$ concurred with the view that it is appropriate to treat cannabis dependence in primary care'.

Pearson's correlations were examined to identify links between GPs who felt primary care was an appropriate setting for treating cannabis dependence with other variables, and links between GPs who felt people presenting with cannabis dependence should be referred to specialist services with other variables.

GPs who felt primary care was an appropriate setting to treat cannabis dependence were more likely to feel confident in their ability to advise patients concerning their cannabis use. Furthermore, they were less likely to believe cannabis is a drug on which people can become dependent and less likely to believe that it leads to mental health complications. These GPs were also less likely to state that abstinence is the best advice they can give their patients and less likely to think that cannabis dependent patients should be referred to specialist services. These correlations are listed in Table 3.

In contrast, GPs who agreed with the statement that 'people presenting to general practice with cannabis-related problems should be referred to specialist drug services' were more likely to assert a need to improve their knowledge of cannabisrelated risks. This group also perceived more risks associated with dependent cannabis use. They were less likely to agree with the statement that cannabis use does not lead to mental health complications and less likely to agree with the statement that cannabis use does not lead an individual to experiment with 'harder drugs'. They also were more likely to disagree with the assertion that it is appropriate to treat cannabis dependence in primary care (Table 4).

Table 3 Pearson's correlations with the variable 'it is appropriate to treat cannabis dependence in primary care'

\begin{tabular}{|c|c|c|}
\hline Variable & $\begin{array}{l}\text { Pearson } \\
\text { correlation }\end{array}$ & $\begin{array}{l}\text { Significance } \\
\text { (2 tailed) }\end{array}$ \\
\hline $\begin{array}{l}\text { I feel confident in my ability to advise patients concerning their } \\
\text { cannabis use }\end{array}$ & +0.268 & 0.008 \\
\hline Cannabis is not a drug on which people can become dependent & +0.236 & 0.020 \\
\hline $\begin{array}{l}\text { People presenting to general practice with cannabis-related } \\
\text { problems should be referred to specialist drug services }\end{array}$ & -0.365 & 0.000 \\
\hline Cannabis use does not lead to mental health complications & +0.256 & 0.011 \\
\hline $\begin{array}{l}\text { Cannabis use does not lead an individual to experiment with } \\
\text { 'harder' drugs }\end{array}$ & +0.414 & 0.000 \\
\hline Abstinence is the best advice I can give to my patients & -0.307 & 0.002 \\
\hline $\begin{array}{l}\text { It would be useful to ask about cannabis use as } \\
\text { part of a 'new patient check' }\end{array}$ & +0.293 & 0.004 \\
\hline
\end{tabular}

Table 4 Pearson's correlations with the variable 'people presenting to general practice with cannabis-related problems should be referred to specialist drug services'

\begin{tabular}{|c|c|c|}
\hline Variable & $\begin{array}{l}\text { Pearson's } \\
\text { correlation }\end{array}$ & $\begin{array}{l}\text { Significance } \\
\text { (2 tailed) }\end{array}$ \\
\hline $\begin{array}{l}\text { I would like to improve my knowledge of the risks associated } \\
\text { with cannabis use }\end{array}$ & +0.228 & 0.025 \\
\hline Cannabis use does not lead to mental health complications & -0.338 & 0.001 \\
\hline $\begin{array}{l}\text { Cannabis use does not lead an individual to experiment with } \\
\text { 'harder drugs' }\end{array}$ & -0.266 & 0.008 \\
\hline It is appropriate to treat cannabis dependence in primary care & -0.365 & 0.000 \\
\hline $\begin{array}{l}\text { Smoking cannabis would be OK if it wasn't for the tobacco that } \\
\text { is smoked with it }\end{array}$ & -0.205 & 0.044 \\
\hline
\end{tabular}




\section{Discussion}

The findings from this study indicate that GPs recognize the potential for harm and dependence associated with cannabis use. This contrasts with wider public views that cannabis is a harmless drug (Ashton, 2001). There is also clear support from GPs to improve their knowledge base and for clarifying treatment options and care pathways.

Our study provides important findings about GPs' attitudes to treating cannabis use in primary care and indicates possible training and service planning needs. Due to the lack of existing research about GPs' views of treating cannabis in primary care, this was an exploratory study that did not identify any specific hypotheses to be tested. However, future research should use logistic regression to examine the different factors and attitudes that predict whether a GP believes cannabis dependence can be treated in primary care or referred on for specialist treatment.

\section{Knowledge, attitudes and current treatment}

Our findings imply that increasing GPs confidence in treating cannabis misuse may lead to increased willingness to be involved in providing treatment in primary care. Taken together with the high levels of uncertainty reported for the value of harm reduction interventions, there are implications for training in this area. Training on cannabis should provide research evidence for effective interventions to cannabis misuse. This should increase confidence of GPs in providing harm reduction interventions in addition to more traditional abstinencebased approaches. It is important, however, to acknowledge the restricted time available to them to provide even brief interventions in allotted appointment times in general practice. Further research is needed to evaluate the most effective way of delivering evidence-based interventions in general practice and incorporated into training programmes.

\section{Onward referral for specialist treatment}

This survey found more support for referring onto specialist drug services than for treating cannabis use in primary care - a finding that is similar to attitudes and treatment responses to opiate users (Glanz, 1986a;1986b). Currently specialist treatment for cannabis misuse is predominantly delivered by a combination of statutory drugs services and voluntary sector organizations. Community Mental Health Teams (CMHTs) are also a principal route of referral by GPs for individuals presenting with mental health complications associated with cannabis use. This reflects the practice and policy of 'mainstreaming' which makes it clear that management of drug use should be delivered within mainstream mental health settings where there is co-existing psychiatric disorder (Department of Health, 2002).

National guidelines make explicit the role of specialist drug services to treat and manage patients with complex needs (Department of Health, 1999). Consequently, referral to such specialist services for cannabis misuse or dependence alone may be inappropriate, as it exposes individuals to a client group with more severe drug misuse histories. This has particular relevance when considering the role of cannabis as a possible gateway drug. Since drug misusers prefer to receive treatment in mainstream settings wherever possible (Department of Health, 1999), it is unlikely that many individuals with cannabis misuse problems alone would find it preferable, if at all acceptable, to access treatment in this setting.

\section{Primary care management}

Despite the preference of GPs in our study to refer on to specialist services, the fact that $46 \%$ $(n=45)$ of GPs reported having been approached by a patient for help with cannabis use illustrates that this is an issue that primary care needs to be equipped to deal with. Effective management of patients in primary care is dependent upon knowledge of evidence-based treatment, available resources to implement this and access to specialist support when needed. We would argue that the ideal situation for management of cannabis misuse in primary care is for all GPs as a minimum to be able to provide two aspects of cannabis-related care. Firstly, GPs should provide harm reduction advice at the point of access regarding an individual's cannabis use and how it affects them. This requires a holistic approach and a need to look at the physical, mental and social well being of the individual and may take the form of a five-minute brief intervention. Some GPs, or other primary care practitioners, may be more able and willing to provide more extended brief interventions to 
address motivation to change using motivational interviewing or stages of change models (eg, Prochaska and DiClemente, 1984). Secondly, GPs need to be able to signpost to other services according to the patients' needs. In addition Primary Care Trusts should investigate ways of incorporating support and treatment for cannabis misuse into existing service models relating to shared care and smoking cessation.

\section{Advice from GPs}

Although this study found GPs' understanding is good overall, it could be improved through specific training courses. Targeting training at primary care practitioners would raise the profile of cannabisrelated harm/dependence as a public health concern and would fit well with the current emphasis on health promotion, prevention and early intervention (Department of Health, 2004).

Improved knowledge of services and treatments could facilitate several further developments in the way that cannabis users could be managed in primary care. Primary care practitioners should advise users about probable ill/adverse effects of cannabis use (Hall and Solowij, 1998) and this should include information relating to mental health problems, dependence, possible role as a 'gateway drug' and respiratory risks of smoking. Of course any discussion around this subject is likely to need a high level of communication skills. In addition there are concerns around confidentiality and recording of personal information in relation to cannabis use in general practice. Despite the reclassification of cannabis from class B to class $\mathrm{C}$ drug, it is still illegal and patients may be reluctant to disclose information GPs need in order to provide good care (Lavender, 1996). Concerns may exist around the accessibility of such information to insurance companies which request medical notes following applications for mortgages or life assurance or employers seeking occupational health information about job applicants.

\section{Brief interventions and the primary care team}

As described earlier, there is evidence to show that cognitive-behavioural interventions and psychosocial support are effective interventions for cannabis misuse (Copeland et al., 2001). Brief interventions for alcohol misuse, a modified cognitive-behavioural approach combined with advice and information, are effective when delivered in primary care. Evidence indicates this approach significantly reduces levels of alcohol use among people with mild to moderate alcohol dependence (Bien et al., 1993). There may well be a similar role for brief interventions for cannabis use delivered in a primary care setting (McCambridge et al., 2003). Additionally, the possibilities of providing specific cannabis services for a local population (as recommended by Stephens et al., 1993) as part of practice based commissioning (PBC), could enable increased access to treatment in primary care. The additional focus on services in primary care, linked to addressing 'lifestyle risks', should improve choice and accessibility for patients in line with the patient choice agenda (Department of Health, 2006).

\section{Effective use of resources and shared care}

Of course there is the question of resource costs (both time and financial) to be considered. At the present time demand for NHS care is at a peak, and additional burdens are likely to be placed upon health care professionals with the new patient choice agenda (Department of Health, 2003). In addition any service development should be underpinned by an analysis of demand and capacity. Whilst GPs' in our sample felt that questions about cannabis use could be asked in a new patient check, at present there is no data about how many people use cannabis in local populations, nor how many need or would access treatment if offered. This needs to be examined further in line with local public health needs assessments.

It may be possible to develop improved help for cannabis users by rethinking current service provision. Firstly, whilst some support and treatment appears to be possible in primary care, the need to access specialist services in both the voluntary and statutory sectors is likely to remain. Protocols for onward referral should be developed and agreed by local PBC hubs or PCTs, and these could build on current local shared care arrangements through existing shared care monitoring groups. Secondly, specialist primary care based workers could be utilised as part of a shared care arrangement with GPs. Shared care schemes are commonplace nationally and whilst they were introduced predominantly to support GPs to prescribe substitute Primary Health Care Research \& Development 2007; 8: 216-225 
treatment for opiate dependent individuals, this model of shared care could be extended to all drug users. Thirdly, closer links with NHS Stop Smoking Services (NHS SSS) would be beneficial. Smoking cessation is a major part of the national health agenda with the investment of $£ 138$ million over the three years 2003-2006 (Department of Health, 2004). There is a high intensity of NHS SSS coverage within geographical areas and a range of health professionals trained and equipped to provide smoking cessation support and advice using a variety of treatment combinations and settings. Practitioners delivering these services should be able to acknowledge that cannabis smoking is not unusual and develop ways of helping cannabis smokers, using evidence-based interventions. This approach would maximise the use of current infrastructure and build upon current public understanding of NHS SSS.

\section{Conclusion}

The findings from this study suggest that GPs are knowledgeable about potential cannabis-related harm and dependence and that many have been and are being approached by cannabis users who wish to stop using the drug. In this study we did not collect demographic data (age, sex) or practice baseline data (list size, special interests) from respondents so we are unable to link findings on attitudes to these variables. However, this study still provides useful information and allows us to consider the efficacy of cannabis misuse treatment in relation to primary care.

The results from this local questionnaire study of Wandsworth GPs have illustrated that whilst cannabis use is recognised as potentially harmful, consensus on treatment does not yet exist. Improved training in cannabis-related issues for primary care team members may improve support provided to cannabis users attending primary care and could link into new national initiatives around PBC and increasing skills of practitioners. However, whilst efforts can be made locally, the absence of clarity of level of harm attributable to cannabis only compounds confusion for many. As such, clear guidance nationally for healthcare professionals providing cannabis advice and treatment interventions would be welcomed to support local initiatives.

Primary Health Care Research \& Development 2007; 8: 216-225

\section{Acknowledgements}

Thanks go to all the GPs in Wandsworth PCT that completed this survey and to Dr Survjit Cheeta who supervised the original dissertation on which this article is based.

\section{References}

Andreasson, S., Allebeck, P., Engstrom, A. and Rydberg, U. 1987: Cannabis and schizophrenia: a longitudinal study of Swedish conscripts. Lancet 2, 1483-86.

Ashton, C.H. 2001: Pharmacology and effects of cannabis: A brief review. British Journal of Psychiatry 178, 101-106.

Bien, T.H., Miller, W.R. and Tonigan, J.S. 1993: Brief interventions for alcohol problems: a review. Addiction 88, 315-36.

Bovasso, G.B. 2001: Cannabis abuse as a risk factor for depressive symptoms. American Journal of Psychiatry 158, 2033-37.

Copeland, J., Swift, W., Roffman, R. and Stephens, R. 2001: A randomised controlled trial of brief cognitive-behavioural interventions for cannabis use disorder. Journal of Substance Abuse Treatment 21, 55-64.

Department of Health. 1999: Drug misuse and dependence Guidelines on clinical management. London: The Stationary Office.

Department of Health. 2002: Mental health policy implementation guide: Dual diagnosis good practice guide. London: Department of Health.

Department of Health. 2003: Choice of hospital: guidance for PCTs, NHS trusts and SHAs on offering patients choice of where they are treated. London: Department of Health.

Department of Health. 2004: Choosing Health: making healthy choices easier. London: The Stationary Office.

Department of Health. 2004: NHS helps over 200000 smokers quit the habit. Press release, 9 July 2004.

Department of Health. 2006: Our Health, our Care, our Say: a new direction for community services. London: The Stationary Office.

De Vaus, D. 2002: Survey research. In Greenfield, T., editor, Research methods for postgraduates. Second edition. London: Arnold, 172-84.

Drugscope. 2000: Drug terms. Retrieved 12 April 2006 from http://www.drugscope.org.uk/DS\%20Media\%20Project/ media_terms.htm.

Eaton, G., Morleo, M., Lodwick, A., Bellis, M.A. and McVeigh, J. 2005: United Kingdom drug situation: annual report to the European Monitoring Centre for Drugs and Drug Addiction (EMCDDA). London: Department of Health.

Fergusson, D.M. and Horwood, L.J. 2000: Does cannabis use encourage other forms of illicit drug use? Addiction 95, 505-20.

Fergusson, D.M., Horwood, L.J. and Ridder, E.M. 2005: Tests of causal linkages between cannabis use and psychotic symptoms. Addiction 100, 354-66. 
Glanz, A. 1986a: Findings of a national survey of the role of general practitioners in the treatment of opiate misuse: dealing with the opiate misuser. British Medical Journal 293, 486-88.

Glanz, A. 1986b: Findings of a national survey of the role of general practitioners in the treatment of opiate misuse: views on treatment. British Medical Journal 293, 543-45.

Hall, W. 1998: The respiratory risks of cannabis smoking. Addiction 93, 1461-63.

Hall, W. and Solowij, N. 1998: Adverse effects of cannabis. Lancet 352, 1611-16.

Hashibe, M., Straif, K., Tashkin, D.P., Morgenstern, H., Greenland, S. and Zhang, Z.F. 2005: Epidemiologic review of marijuana use and cancer risk. Alcohol 35, 265-75.

Henry, J.A. 2003: Comparing cannabis with tobacco. British Medical Journal 326, 942-43.

Home Office. 2002: Updated Drug Strategy. London: The Stationary Office.

Iverson, L.L. 2000: The Science of Marijuana. Oxford: Oxford University Press.

Kmietowicz, Z. 2002: GPs asked to do more for drug misusers. British Medical Journal 324, 501.

Lavender, H. 1996: Controversies in management: Access should be denied. British Medical Journal 313, 286-87.

Linszen, D.H., Dingemans, P.M. and Lenior, M.E. 1994: Cannabis abuse and the course of recent-onset schizophrenic disorders. Archives of General Psychiatry 51, 273-79.

Mathers, D.C. and Ghodse, A.H. 1992: Cannabis and psychotic illness. British Journal of Psychiatry 161, 648-53.

Matheson, C., Pitcairn, J., Bond, C.M., Van Teijlingen, E. and Ryan, M. 2003: General practice management of illicit drug users in Scotland: a national survey. Addiction 98, 119-26.

McCambridge, J., Strang, J., Platts, S. and Witton, J. 2003: Cannabis use and the GP: brief motivational intervention increases clinical enquiry by GPs in a pilot sudy. British Journal of General Practice 53, 637-39.
McGillion, J., Wanigaratne, S., Feinmann, C., Godden, T. and Byrne A. 2000: GPs attitudes towards the treatment of drug misusers. British Journal of General Practice 50, 385-86.

Melamede, R. 2005: Cannabis and tobacco are not equally carcinogenic. Harm Reduction Journal 2, 21.

National Treatment Agency. 2005: Update 8. National Treatment Agency for Substance Misuse.

Patton, G.C., Coffey, C., Carlin, J.B., Degenhardt, L., Lynskey, M. and Hall, W. 2002: Cannabis use and mental health in young people: cohort study. British Medical Journal 325, 1195-98.

Prochaska, J.O. and DiClemente, C.C. 1984: The transtheoretical approach: Crossing the traditional boundaries of therapy. Melbourne: Krieger Publishing Company.

Rey, J.M. and Tennant, C.C. 2002: Cannabis and mental health. British Medical Journal 325, 1183-84.

Robson, P. 1998: Cannabis as medicine: time for the phoenix to rise? British Medical Journal 316, 1034-35.

Stephens, R.S., Roffman, R.A. and Simpson, E.E. 1993: Adult marijuana users seeking treatment. Journal of Consulting and Clinical Psychology 61, 1100-104.

Stephens, R.S., Roffman, R.A. and Simpson, E.E. 1994: Treating adult marijuana dependence: a test of the relapse prevention model. Journal of Consulting and Clinical Psychology 62, 92-99.

Swift, W., Hall, W., Didcott, P. and Reilly, D. 1998: Patterns and correlates of cannabis dependence among long-term users in an Australian rural area. Addiction 93, 1149-60.

Wandsworth Primary Care Trust. 2004: Health in Wandsworth: the independent annual report of the director of public health. London: Wandsworth PCT.

Wu, T., Tashkin, D.P., Djahed, B. and Rose, J.E. 1988: Pulmonary hazards of smoking marijuana as compared with tobacco. New England Journal of Medicine 318, 347-51. 